
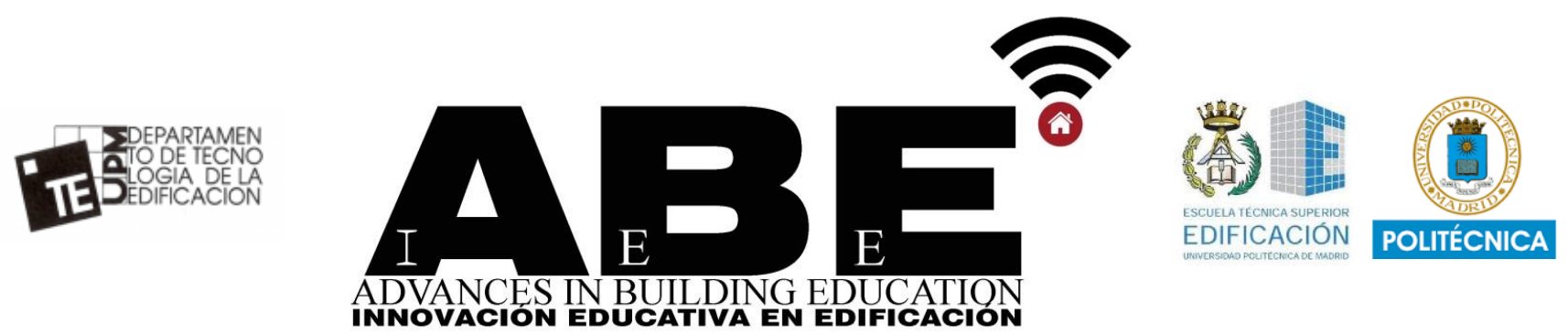

\title{
Methodology to evaluate school buildings. Educational applications
}

\author{
Montserrat Irene Ros-Martín ${ }^{1 *}$ \\ 1 Universidad Rey Juan Carlos. Madrid (España) \\ Irene.ros@urjc.es
}

Recibido: 09/10/2021 | Aceptado: 08/11/2021 | Fecha de publicación: 21/12/2021

DOI:10.20868/abe.2021.3.4734

\section{HIGHLIGHTS}

- The age of the current schools, as well as the lack of conservation actions and the scant research about their technical conditions, leads to the question of whether the school buildings ensure the welfare and protection of their users.

- In this work, a methodology to assess if school buildings keep to the technical requirements of current legislation and how we can use them in university teaching is presented.

- This scalable and replicable methodology can be applied by Architecture students to any building and project depending on the use after making adaptations in scales of assessment and analysis of results.

\section{ABSTRACT}

In this work, an innovative methodology to assess the security, habitability and functionality requirements of school buildings have been designed. The objectives are two: to design an evaluative methodology to assess technically the satisfaction of the basic requirements: safety, habitability and functionality that exist in public school buildings, and apply the methodology developed in university teaching so that students of the disciplines related to construction are able to justify, based on the regulations, their project decisions and intervention. The methodology is developed in the subject Applied Construction of the Master in Architecture of the Rey Juan Carlos University. The main result is that, from the detection of a real problem, such as the state of conservation of school buildings, we can developed an educational practice that helps Master students to ensure that their projects comply with current regulations. One of the most relevant conclusions is that the teaching applications of a real research, offer a provided value at academic level and a realistic view of the current constructions. 
Furthermore, stress the importance of both planning in accordance with the regulations and ensuring the conservation of the buildings.

Keywords: School construction, Educational architecture, Teaching methodology, Master in Architecture, University educational innovation

\section{INTRODUCTION}

Traditionally, the spaces of the schools have been the focus of attention of prestigious pedagogues, teachers and philosophers. Educational spaces, understood as a social ecosystem, define and shape culture, projecting

values and priorities on the educational community [1]. Space provokes sensations, and influences not only learning, but also behaviours and relationships between children [2]. Numerous neuroscientific studies oriented to architecture and education highlight the importance that school architecture has over the educational process. They show that the design of educational spaces must stimulate learning [3] and, at the same time, provide a safe and affective environment for the people who inhabit them [4]. School buildings must have a high degree of quality, both in their conservation and in their aesthetics, so that children are physically and psychologically safe [5]. In addition, the care of the places where you learn motivates students to feel important within their academic environment

School architecture has evolved slowly in recent decades [6]. Most of the public school buildings that are operating in Spain were designed and built based on the normative and educational specifications of the last quarter of the twentieth century and are still formed as homogeneous and closed spatial units that do not offer the possibility of interaction between them or with the outside. Likewise, there has been no national plan for the comprehensive rehabilitation of these educational spaces, and both their maintenance and conservation have been scarce. All this makes it necessary to evaluate the architectural programs of public schools [7] in order to obtain conclusions about the state of conservation of the same, in such a way as to guarantee their enjoyment by children in a safe, healthy and inclusive way [8].

School architecture is becoming increasingly important both in scientific publications and in political agendas [9] and in almost all of them, the importance of renewing educational spaces to adapt them to the demands of the current era is highlighted. In this sense, some parameters of evaluation of existing architectural spaces have been found [1] [5] [10] that are mainly related to environmental and aesthetic issues, as well as experiences and methods to transform these spaces according to pedagogical needs [11] [12]. With an eminently technical character, which enters to assess the conditions of the school constructions according to the regulations, the only reference is the study carried out by Rodríguez-Fuentes and Rodríguez-Fuentes [7] about the evaluation of the spaces of a Vocational Training centre.

The age of current schools, together with the lack of conservation actions and the scarce research about their technical conditions leads to the question if school buildings guarantee the wellbeing and protection of their users. All buildings comply with these guarantees when they satisfy the basic requirements (BR) of safety, habitability and functionality contemplated in the Building Planning Law (BPL) [13] and these, in turn, are 
verified through compliance with current legislation on construction, protection and, in the case of school constructions, education.

There are several ways to check compliance with the legislation. In this article, a methodology that allows evaluating if school constructions satisfy the technical requirements of current regulations and how it can be used in university teaching is presented. It focuses exclusively on the technical conditions, precisely because of the educational possibilities it has in the Degrees associated with the building. However, with the relevant adaptations, it is part of a global methodology that allows the assessment of the BR in all areas of the building.

The objectives, therefore, of this work are: (1) the design of an evaluation methodology that allows to technically assess the satisfaction of the basic requirements of safety, habitability and functionality of existing public school buildings and (2) the application of the methodology developed in university teaching so that students of the disciplines related to building are able to justify, based on the regulations, their project and intervention decisions.

\section{METHODS}

The methods followed to achieve the proposed objectives are divided into two phases, according to the nature of each of them. First, the methodology for evaluating school buildings that any competent technician in building can apply in their professional work is defined and their teaching application is described.

\subsection{Evaluation instrument to assess school constructions}

The design of the evaluation instrument has required the following methods: (1) Literature review of the current regulations on construction, protection and education; (2) Definition of the parameters applicable to school constructions; (3) Development of information collection tools; (4) Establishment of the rating scale; (5) Assessment of parameters; (6) Analysis of the results. Next, each of them is developed.

\subsubsection{Literature review}

The scope of the search for laws has been carried out at four levels, in hierarchical order: international, European, national and autonomous community of Madrid (CM). The search terms used have been: "school buildings", "educational spaces", "school architecture", "teacher" and "school building". Filters have been applied so that these terms are found in the title, in the text, or in both. As assessment parameters, all aspects of these areas that concern the BR have been taken. In the absence of international and European regulations in the fields of study, provisions of national and regional application of the CM have been considered (Table 1). Of all the laws examined only those that allow assessing technical requirements in school constructions have been selected:

At the national level, two in the constructive field: (-) Law 38/1999, of November 5, on Building Planning Law (BPL) [13] and (-) Royal Decree $314 / 2006$, of March 17, which approves the Technical Building Code (BTC) [14]; one in the educational field: (-) Royal Decree 132/2010, of February 12, which establishes the minimum requirements of the centres that teach the second cycle of Early Childhood Education, Primary Education and Secondary Education (RD 132/2010) [15]; and two in terms of protection in case of emergency: (-) Royal Decree 393/2007, of 23 March, approving the Basic Standard of Self-Protection of centres, establishments and dependencies dedicated to 
activities that may give rise to emergency situations (RD 393/2007) [16] and (-) Royal Decree 513/2017, of 22 May, approving the Regulation on fire protection installations (RD 513/2017) [17].

At the regional level, one in terms of protection: (-) Decree 74/2017, of August 29, of the Governing Council, which creates and regulates the operation of the Data Registry of SelfProtection Plans of the Community of Madrid (D74/2017) [18].

\subsubsection{Definition of parameters}

Table 1: Abstract of the legislation consulted

\begin{tabular}{|c|c|c|}
\hline Law & National & Autonomic \\
\hline Construction & $\mathrm{BPL}$ & \\
& $\mathrm{BTC}$ & \\
\hline Protection & $\mathrm{RD}$ & $\mathrm{D} 74 / 2017$ \\
& $393 / 2007$ & \\
& $\mathrm{RD}$ & \\
& $513 / 2017$ & \\
\hline Education & $\mathrm{RD}$ & \\
& $132 / 2010$ & \\
\hline
\end{tabular}

From each law, the parameters that respond to the regulatory requirements associated with school constructions have been extracted. They have been drafted in such a way that their wording in the legislation is modified as little as possible and, at the same time, they admit a dichotomous assessment yes/no. They have then been codified following the pattern P.n, where the letter $P$ indicates a code with acronyms, by which it is known, or has been established for this research, and the letter $n, a$ correlative order number assigned as found in the normative text. In the case of the Basic Documents (BD) of the BTC, the section to which the parameter belongs has also been added. The coding of acronyms and the order followed has been: BPL, BTC, RD 393/2007 and D74/2017 (AP), RD 513/2017 (FPI) and RD 132/2010 (MR).

Three parameters have been extracted from the BPL. The BTC has examined those BD that address issues specifically related to compliance with the basic requirements of the teaching building, that is, in some way, are related to the places of learning. In total, there have been 169 parameters: BD Fire Safety (SI), 34 parameters; BD Security of Use and Accessibility (SUA), 93 parameters; of the BD Health Standards (HS), 17 parameters; of the BD Energy Saving (HE), 16 parameters; and BD Noise Protection (HR), 9 parameters. From RD 393/2007 and Decree 74/2017, as they are closely related, 15 AP parameters have been obtained together. From RD 513/2017, two FPI parameters have been extracted. Finally, 26 MR parameters have been taken from RD 132/2010. In total, 212 parameters to be assessed have been extracted.

Once the parameters have been determined, it has been connected to which one or which of the three BR it responds, in order to analyze in a more rigorous way the satisfaction of these. The relationship has been made in an objective way, according to the purpose described in each of the regulations.

As an example, a parameter of each of the regulations examined is enunciated with the $B R$ to which it responds:

BPL.1. The arrangement of the spaces facilitates the adequate performance of the teaching function. BR: Functionality

SI 3.1. The occupancy density of the whole floor or building is $\geq 10 \mathrm{~m}^{2} /$ person. BR: Security SUA 2.7. The sweeping of the door leaves does not invade corridors of width $\leq 2.50 \mathrm{~m}$. BR: Safety + Functionality

HS 3.1. The total practicable surface of windows and exterior doors of each educational space is, 
at least, $1 / 20$ of the useful surface of the same. BR: Habitability

HE 3.4. The areas of sporadic use have an on and off system by timed presence detection system or timed pushbutton system. BR: Habitability

HR.4. The construction systems of horizontal separation elements comply with the limit values for sound insulation to airborne noise. BR: Habitability

AP.12. The school has a program to maintain the effectiveness and update of the Self-Protection Plan. BR: Security

FPI.1. The first inspection of the existing fire protection facilities has been carried out based on RD 513/2017, of May 22. BR: Security

MR.21. The area of the courtyard is $\geq 900 \mathrm{~m}^{2}$. BR: Security + Functionality

\subsubsection{Development of information collection tools}

To assess each parameter in an objective way, various information collection instruments have been used. The direct observation in the schools was the main one, although historical, technical and graphic documentation available about the educational centres and the preparation of technical reports were also necessary. Each parameter has been associated with the instrument or instruments that must be used for its assessment.

Direct observation is the instrument with which more information is collected. The technical inspection in the educational centres allows to know the school constructions and their state of general conservation. This system has been associated with the collection of evidence such as photographs, measurements and sketches. In case of using them, it is necessary to encode and register them to achieve traceability in the collection of information.
The consultation of historical, technical and graphic documentation helps to assess certain parameters and, at the same time, to understand the current situation of school constructions. Historical documentation is drawn from books and informational articles. The technical documentation relating to maintenance, facilities and supplies is used to know the state of conservation of school buildings. Consulting this documentation helps to assess certain parameters that are not directly observable in buildings. Graphic documentation is necessary to understand the spatial configuration of buildings. Original architectural projects are usually found in the Municipal Archives. If the original documentation of the schools is not found, the projects of type schools with the same characteristics can be used, as well as the graphic documentation available in the SelfProtection Plans of the schools.

The assessment of the parameters extracted from the BTC and related to energy saving (BTC $\mathrm{BD}-\mathrm{HE})$ and noise (BTC BD-HR) requires a technical justification according to the specifications of said regulations. These are technical reports that do not have an official character, but intend to show those required data that allow the assessment of the corresponding parameters. Implementation guides, supporting documents and appendices to the BTC have been used for its preparation. Technicians can use any of the software validated by the Ministry for the Ecological Transition and the Demographic Challenge. In this case, for the justification of the DB-HE, the CE3X v2.3 application and its ISOVER complement for the Verification of the BTC, iCONECTA, in its November 2020 version, have been chosen as support. With regard to DB-HR, the CTEWeb application, developed by the Eduardo Torroja Institute of Construction Sciences and the Construction Institute of 
Castilla y León (ICCL), has been used. All of them are available for free.

\subsubsection{Establishment of the rating scale}

The rating scale of the parameters has been established with four levels: yes / no / no exists / not checked. The first two give a direct response to the fulfilment or not of the requirement. The other two levels respond to the possible situations that may occur in an inspection. The 'does not exist' level has been created for those cases in which the regulations reflect the requirements of a certain element that is not in the building, such as an elevator. The 'not checked' level is used in those cases where it is impossible to determine whether the requirement is test with the available resources. This is the case of access to certain areas of the construction, such as the facility skids and roofs. It is also used if you do not have the technical and / or graphic documentation to check a requirement.

\subsubsection{Assessment of parameters}

Each parameter is associated with one or more previously defined information collection instruments. The parameters that are assessed by direct observation require an inspection in the educational centre, which may consist of one or several days. It is advisable to have studied the available documentation before carrying out the inspection at the school. The assessment of these parameters can be done as the inspection is carried out.

Once the inspection is finished, the rest of the parameters are assessed through the evidence collected through the various channels: photographs, plans, documents and technical reports. Each of these evidences must have an assigned code to ensure traceability. Each technician can apply the one he prefers, although it is recommended to order them according to the order of the parameters, so that their correspondence is simpler and their consultation more agile.

In addition to the evidence, if necessary, it is planned to add observations that justify the assessment or that propose suggestions for improvement.

\subsubsection{Analysis of the results}

The results are analysed in two ways: quantitatively and qualitatively. Quantitative analysis provides an overview of the state of the building. Qualitative analysis provides detailed information about the parameters for action.

The table 2 has been designed to perform quantitative analysis. In it, it is indicated, for the BR of safety $(\mathrm{S})$, habitability $(\mathrm{H})$ and functionality $(F)$ the number $(n)$ and the percentage (\%) of parameters that have obtained each of the levels $(L)$ in the rating scale: yes / no / no exists $(\nexists)$ / not checked (NC).

Table 2: Quantitative results

\begin{tabular}{|c|c|c|c|c|c|c|c|c|}
\hline L & \multicolumn{2}{|c|}{ YES } & \multicolumn{2}{c|}{ NO } & \multicolumn{2}{|c|}{ \# } & \multicolumn{2}{c|}{ NC } \\
\hline BR & $\mathrm{n}$ & $\%$ & $\mathrm{n}$ & $\%$ & $\mathrm{n}$ & $\%$ & $\mathrm{n}$ & $\%$ \\
\hline S & & & & & & & & \\
\hline H & & & & & & & & \\
\hline F & & & & & & & & \\
\hline
\end{tabular}

Once the count of each level has been made and its percentage applied, the degree of adequacy of the school construction to each basic requirement is established: high, medium and 
low. These have been determined according to three premises:

$P 1$. The degree of satisfaction of a requirement cannot be established if there are more than $20 \%$ of parameters no checked (NC). The lack of data implies that the impossibility of objectifying the requirement.

P2. Whether the parameter is not achieved or does not exist, it is counted as 'no'. This decision is justified because if the element that is being evaluated does not exist, but in the regulations it is contemplated that it must exist, it is a breach (it is the case of the elevator contemplated above). There is an exception to this premise. When the normative parameter is not applicable in one or more of the buildings of the enclosure by surface limits, or the element does not exist, such as parking, the valuation 'does not exist' is justified as 'does not apply' in the column of observations, and is counted.

P3. Those requirements that obtain less than $50 \%$ of valuations with 'yes', are qualified as noncompliance. This is because it is about complying with legislation, and ensuring the well-being of the users of the school building, among which the largest number of people are minors, boys and girls.

Once the premises are applied, the quantitative analysis is performed. The construction obtains a high degree of adequacy to the BR if it obtains more than $85 \%$ of valuations with 'yes'; an average degree of adequacy if the percentage of 'yes' ratings is between $70 \%$ and $84 \%$; and a low degree if the percentage of 'yes' was between $50 \%$ and $69 \%$. This first assessment allows to classify the schools by grades according to their adequacy to the basic requirements.

Qualitative analysis allows to obtain detailed information on the situation of each school. Its achievement allows: to identify the parameters that, even if achieved, can be improved; know why certain parameters have not been achieved or do not exist; explain the reasons why some of the parameters have not been checked.

To carry out this analysis, the parameters that are subject to review are related, accompanied by their assessment, the reason why they have not complied and their justification. It is also recommended to add proposals for correction and improvement.

This methodology can be used to assess the technical satisfaction of the BR to any public school of Early Childhood and Primary Education. In the same way, and with the corresponding regulatory adjustments, it is replicable in any building, whatever its use.

\subsection{Teaching applications of the methodology}

Beyond the professional application, the methodology designed offers a great opportunity to work with university students and that they are able to check if their projects satisfy the BR and comply with current regulations. In fact, this methodology is likely to be developed in various didactic actions of both Degree and Master and both in more technical subjects and in subjects more focused on the design of projects.

Next, one of its teaching applications is described, which is carried out in the subject Applied Construction of the Master's Degree in Architecture of the Rey Juan Carlos University, which is enabling the profession. It is a quarterly subject that is taught in the second semester of the course and whose nature is eminently practical. It is aimed at students solving the constructive part of their final master projects (FMP). The objectives pursued in it are: (-) To know and apply the current regulations on 
construction, regardless of the program that is defined for the building; (-) Investigate traditional and innovative materials, products and construction systems in building; and (-) Define and develop constructive solutions adopted to the architectural project.

To achieve these objectives, project-based learning (PBL) is applied. Students are projecting their FMPs in parallel subjects and, at the same time, they are defining their construction, since they are actions that are, inevitably, linked. The first four sessions of the subject are intended for the application of the methodology to evaluate school constructions, adapted to the needs of each project. The remaining six sessions are organized as group tutorials in which students present the progress of their work and correct the aspects to improve. The learning results in constructive terms are materialized in a constructive section at 1/50 scale, ten constructive details extracted from this section and two plans of justification in plant of the DB-SI and DB-SUA. The evaluation is continuous and two pre-deliveries are scheduled in which feedback of the work is offered to each of the students. The final delivery contains all the requested sections.

The way in which an adapted version of the methodology to assess school constructions is applied in edification teaching is described below.

(1) Literature review of the regulations. First, the legislation applicable to the projects is determined based on their situation and nature. Students are divided into teams and each is assigned a regulation. In the case of the BTC, a DB is assigned to each group.

(2) Definition of the parameters applicable to the projects. The obtaining of the parameters that are applicable to the projects and reflect them in a collaborative document is explained. Then, all students have the complete list of parameters. This step is important, because students realize the limitations that the regulations impose on their project decisions and understand that, if they know these limitations before fully defining the project, they gain time and advance work.

Architectural programs may not be exactly the same in all projects, as the statement always reserves a certain area without program specification for them to choose from. That is why, in this phase, students are invited to contemplate all the possibilities depending on the use.

(3) Relationship between regulatory parameters and basic requirements. This step is simple, since it is only a matter of assigning the BR to the parameters that they have selected according to the specifications of the regulations themselves.

(4) Development of information collection tools. In this phase, a greater adaptation is required, since their projects are not built and, therefore, the instruments are not used as in the original methodology.

Direct observation is not applied in an on-site inspection, but is determined on the designs. In this case, evidence is also not necessary.

The documentation query is exclusively graphic and is the one that they themselves generate in their project.

The preparation of technical reports is essential, especially to justify that the constructive solutions defined comply with the parameters of the BD-HE and the BD-HR. The software to prepare the reports are the aforementioned CE3X v2.3 and its ISOVER complement for the Verification of the BTC, iCONECTA, in its November 2020 version for the BD-HE and the CTEWeb application for the BD-HR. 
(5) Establishment of the rating scale. As in the previous step, as these are no built projects that are also being developed according to the regulations, it is enough to work with a dichotomous yes/no scale.

(6) Assessment of the parameters. At this point, students are given two options: establish what parameters affect them in their project decisions, and make the design taking them into account or make the design and then check if these parameters are met or not. In any case, as the projects are constantly modified throughout the development of the Master, it is recommended that everyone verify compliance with the parameters before the final delivery.

(7) Analysis of the results. Thanks to this final verification, quantitative analysis is not necessary, as they must meet all the parameters. However, qualitative analysis is useful, as it allows them to propose suggestions for improvement in projects, or possible alternatives to their project decisions.

Once the methodology has been applied, students are in a position to complete their delivery of construction plans, which are evaluated through a rubric with four levels: not delivered / not achieved / in development / achieved. The items to be evaluated are: (-) The section has defined all the constructive systems of the building; (-) The construction section meets the criteria of stability, thermal envelope and tightness; (-) At least ten constructive details of the section are defined; (-) The graphical representation of the details is correct (textures, dimensions, names, scale); (-) The construction systems used are correctly defined; (-) The BDSI plant justification is correct; (-) The plant justification for BD-SUA is correct.

\section{RESULTS AND DISCUSSION}

The main result of this article is that, from the detection of a real problem, such as the state of conservation of school buildings, an educational practice has been developed that helps Master's students to ensure that their projects comply with current regulations. The other results are expressed in terms of research and teaching.

The results of the research are related to the usefulness of the methodology designed. Its application is the starting point to give visibility to a current problem that affects one of the most sensitive groups in society: children. Thanks to it, the necessary information is obtained to determine if the school constructions comply with the basic requirements of safety, habitability and functionality established in the current regulations that affect them. In this way, it is possible to act accordingly to ensure that the necessary adaptations are made, ensuring spaces of well-being and protection for children.

Before applying the methodology, it is interesting to have and consult the maximum possible documentation of the school constructions to be inspected. The memory and plans, the building book, the maintenance program and actions, the inspection and review reports of facilities, and the self-protection plan are very useful. If there is not enough documentation, it is necessary to interview municipal technicians and the school's own management team, in order to gather as much information as possible.

During the application, it must be taken into account that it is not possible to firmly ensure compliance with some functionality requirements, because the technical observers are not members of the educational community who enjoy the spaces on a daily basis. This aspect was also included in the study of Rodríguez-Fuentes and Rodríguez-Fuentes [7], who contemplated the consultation of different 
users of the Professional Formation Centre to know their perception.

On the other hand, the methodology has been designed taking into account the regulations of the CM. There are other Autonomous Communities that are working on specific legislation on school constructions, such as Catalonia and Galicia, so it should be consulted if it is applied outside Madrid. Similarly, if it were to be applied in other types of buildings, it would be necessary to review and adapt the parameters corresponding to the use.

The methodology is structured for any technician to understand, and offers a large amount of information regarding the state of conservation of the school construction, compatible with the evaluation report of the building that is carried out through the Ministry of Development.

It is important to note that the methodology has been carried out following the current regulations in force, and that it would be desirable, following Crespo and Lorenzo [8], that the legislation on school constructions was one more tool to contemplate in the educational system. The most propitious thing would be that there be a specific regulation on school constructions, not only of new construction, but existing, in order to ensure their adaptation to the basic requirements.

From the teaching point of view, the methodology to assess school constructions has great potential. It is characterized by great versatility. It is scalable and replicable to any building, choosing the corresponding parameters depending on the use and making the adaptations in scales of assessment and analysis of results.

It can be applied to both the built building and the projected building, which makes it suitable for subjects in the fields of rehabilitation, construction and projects.

In the teaching practice of the subject Applied Construction, optimal results have been observed in the students' projects. After applying the methodology adapted to their projects, students are certain that the constructive solutions adopted comply with current regulations and satisfy the basic requirements, which reinforces not only the resolution of the construction but the coherence of the project.

\section{CONCLUSIONS}

The objectives established for this article have been achieved, since an evaluation methodology has been designed that allows to technically assess the satisfaction of the basic requirements of safety, habitability and functionality of existing public school buildings and this has been applied in university teaching so that students of the Master's Degree in Architecture develop their projects in compliance with the regulations and the BR.

The methodology designed provides an information base on which to start working on a plan of action and improvement of public school constructions. It is approached from the technical and academic point of view, but it aims to be an instrument thanks to which the need to adapt educational centres to the basic requirements is highlighted.

In fact, the ideal scenario is that the interventions to be carried out in the school constructions, in addition to having a technical component, contemplate both the educational project of the centre and the interests of its educational community. Likewise, it should be governed by the principles of inclusion and interconnection between environment and person to be adapted 
to the needs that users need both individually and socially [8].

To obtain the maximum possible information through the designed methodology, it is necessary to combine several actions, such as visual and technical inspection, consultation of documentation and conducting interviews with the educational community. These are the users who enjoy school buildings on a daily basis and who know their reality.

Lord Kelvin enunciated "what is not defined, cannot be measured. What is not measured, cannot be improved. What is not improved, is always degraded." It is necessary to know the state of the school constructions, improve them to adapt them to the fulfilment of the basic requirements, and thus avoid their degradation and loss. If at the same time they become motivating spaces towards learning, they will be ensuring the well-being of children.

These reflections also add value at the academic level when students are transmitted the nature of the methodology they are using. In this way, its usefulness does not lie only in the facilitation of the development of projects, but also provides a realistic vision of what has been built and emphasizes the importance of both designing according to the regulations and ensuring the conservation of the constructions.

\section{REFERENCES}

[1] Ruiz, J.M. (1994). The school space. Revista Complutense de Educación, vol, 5(2), pp. 93104

[2] Cabanellas, I., Eslava, C. (2005). Childhood territories. Dialogues between architecture and pedagogy. Barcelona: Grao

[3] Montiel, I. (2017). Neuroarchitecture in education. An approach to the state of the matter. Doctorate Journal UMH. 3(2), pp. 6-16. [Online]

[4] Mora, F. (2013). Neuroeducation. You can only learn what you love. Madrid: Alianza Editorial

[5] Crespo Comesaña, J. \& Pino-Juste, M. (2010). The aesthetics of school buildings in Early Childhood Education in the Autonomous Community of Galicia. Journal of Education, 351, pp. $485-511$

[6] Mombiedro, A. (2019). Impact of the spaces on methodologies, impact on student motivation and teaching. Journal of Educational Management and Leadership, 4, pp. 19-22

[7] Rodríguez-Fuentes, A. \& Rodríguez-Fuentes, L. (2016). Algorithm for evaluating the educational potential of architectural spaces in Vocational Training centers. Journal of Education of the University of Granada, 23, 133148

[8] Crespo Comesaña, J. and Lorenzo Moledo, M. (2015). The spaces of the inclusive primary school: connections and disharmonies between the regulations of school constructions and the purposes of the educational system. Staff. Journal of Pedagogy, 68 (1), pp. 131-144. https://doi.org/10.13042/Bordon.2016.68108

[9] Martire, A. (2017). Doctoral Thesis Media innovation and school architecture. The transformation of learning spaces in secondary school. Autonomous University of Barcelona. http://hdl.handle.net/10803/457721

[10] Nair, P. (2016). Design of educational spaces. Redesign schools to focus learning on the learner. Madrid: SM

[11] Teba-Fernández, E.M., Caballero-García, P. and Bueno-Villaverde, A. (2020). SHINE(R): 
model for the transformation of educational spaces. Journal of Learning Styles, 13(25), pp. 14-28

[12] Albert-Esteve, Á.M. (2019). The educating space: the transformation of children's educational spaces. REDINE (Ed.) Proceedings of Conference Proceedings CIVINEDU 2019, pp. 399

[13] Central Office (1999). Law 38/1999, of November 5, on Building Planning Law, Official State Bulletin

[14] Ministry of Housing (2007). Royal Decree $314 / 2006$, of March 17, which approves the Technical Building Code, Official State Bulletin

[15] Ministry of Education (2010). Royal Decree $132 / 2010$, of February 12, which establishes the minimum requirements of the centres that teach the second cycle of Early Childhood Education, Primary Education and Secondary Education, Official State Bulletin

[16] Ministry of Interior (2007). Royal Decree $393 / 2007$, of 23 March, approving the Basic Standard of Self-Protection of centres, establishments and dependencies dedicated to activities that may give rise to emergencies, Official State Bulletin

[17] Ministry of Economy, Industry and Competitivity (2017). Royal Decree 513/2017, of 22 May, approving the Regulation on fire protection installations, Official State Bulletin

[18] Office of Presidency, Justice $y$ Spokesperson of the Government of the Community of Madrid (2017). Decree 74/2017, of August 29, of the Governing Council, which creates and regulates the operation of the Data Registry of Self-Protection Plans of the Community of Madrid, Official Community of Madrid Bulletin 